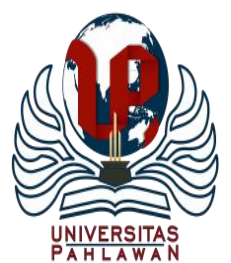

Edukatif : Jurnal Ilmu Pendidikan Volume 3 Nomor 5 Tahun 2021 Halm 2886 - 2897

EDUKATIF: JURNAL ILMU PENDIDIKAN

Research \& Learning in Education

https://edukatif.org/index.php/edukatif/index

\title{
Studi Analisis Pemanfaatan Whatsapp dalam Pembelajaran Daring Akidah Akhlak pada Siswa Madrasah Aliyah
}

\author{
Fikri Firmansyah $^{1 凶}$, Muhamad Taufik Bintang Kejora ${ }^{2}$, Akil $^{3}$ \\ Universitas Singaperbangsa Karawang, Indonesia ${ }^{1,2,3}$ \\ E-mail : $\underline{\text { firmansyahfikri411@gmail.com }}{ }^{1}, \underline{\text { muhamad.taufik@fai.unsika.ac.id }}{ }^{2}, \underline{\text { akil@ @ai.unsika.ac.id }}^{3}$
}

\begin{abstract}
Abstrak
Whatsapp menjadi salah satu media komunikasi yang dimanfaatkan sebagai media pembelajaran daring selama berlangsung kebijakaan belajar dari rumah di masa pandemic. Penelitian ini bertujuan menganalisa keterampilan mengajar guru, keterlaksanaan pembelajaran berbasis Whatsapp oleh guru dan siswa, kendala-kendala yang dihadapi, kepuasan siswa dan hasil belajar siswa pada mata pelajaran Akidah Akhlak. Penelitian merupakan penelitian survei kuantitatif melibatkan 35 siswa kelas X MAS Ghoyatul Jihad Karawang. Pengumpulan data melalui survey melalui googleform, dokumentasi, dan wawancara. Hasil penelitian menunjukkan bahwa pemanfaatan Whatsapp sebagai media pembelajaran mampu secara efektif memfasilitasi kebutuhan belajar siswa madrasah Aliyah pada mata pelajaran Akidah Akhlak di masa pandemic. Keterampilan mengajar dan kemampuan guru mengelola pembelajaran dengan berbantuan Whatsapp menjadi faktor kunci dalam kesuksesan pembelajaran. Penilaian siswa mengenai pembelajaran menggambarkan bahwa guru sudah mampu mengaplikasikan Whatsapp dan mengkolaborasikannya dengan media pendukung lainnya dalam pembelajaran. Kendati siswa mengalami kesulitan akses internet dan kuota serta merasakan menumpuknya tugas, namun pada kenyataannya siswa mampu mengumpulkan tugas dengan baik, merasa puas dengan pembelajaran yang dilaksanakan dan berhasil memperoleh hasil belajar yang memuaskan/baik secara kumulatif/klasikal.
\end{abstract}

Kata Kunci: Pembelajaran Daring, Akidah Akhlak, Whatsapp.

\begin{abstract}
Whatsapp is one of the communication media that is used as a learning medium during the study from home policy during the pandemic. This study aims to analyze the teacher's teaching skills, the implementation of Whatsapp-based learning by teachers and students, the obstacles faced, student satisfaction and student learning outcomes in the Akidah Akhlak subject. This research is a quantitative survey research involving 35 students of class X MAS Ghoyatul Jihad Karawang. Collecting data through surveys through google form, documentation, and interviews. The results showed that the use of Whatsapp as a learning medium was able to effectively facilitate the learning needs of Madrasah Aliyah students in the Akidah Akhlak subject during the pandemic. Teaching skills and the ability of teachers to manage learning with the help of Whatsapp are key factors in learning success. Student assessment of learning illustrates that teachers have been able to apply Whatsapp and collaborate with other supporting media in learning. students have difficulty accessing the internet and quotas and feel their assignments, but in reality students are able to collect assignments well, feel satisfied with the learning carried out and succeed in obtaining satisfactory/good natural/classical learning outcomes.
\end{abstract}

Keywords: Online Learning, Akidah Akhlak, Whatsapp.

Copyright (c) 2021 Fikri Firmansyah, Muhamad Taufik Bintang Kejora, Akil

$\triangle$ Corresponding author

Email : firmansyahfikri411@gmail.com

DOI : https://doi.org/10.31004/edukatif.v3i5.1018

ISSN 2656-8063 (Media Cetak)

ISSN 2656-8071 (Media Online)

Edukatif : Jurnal Ilmu Pendidikan Vol 3 No 5 Tahun 2021 p-ISSN 2656-8063 e-ISSN 2656-8071 
2887 Studi Analisis Pemanfaatan Whatsapp dalam Pembelajaran Daring Akidah Akhlak pada Siswa Madrasah Aliyah - Fikri Firmansyah, Muhamad Taufik Bintang Kejora, Akil

DOI: https://doi.org/10.31004/edukatif.v3i5.1018

\section{PENDAHULUAN}

Sejak diberlakukannya Learning From Home yang diintruksikan oleh Pemerintah pusat melalui Kementerian Pendidikan dan Kebudayaan dengan dikeluarkannya Surat Edaran Nomor 4 tahun 2020 tentang Pelaksanaan Pendidikan Dalam Masa Darurat Corona Virus Disease (COVID - 19), pendidikan di Indonesia menerapkan pembelajaran Jarak Jauh (PJJ) kepada siswa (Novianti E et al., 2020). Pandemi Covid-19 berdampak pada sedikitnya ada 127 juta sekolah di dunia. Di Indonesia, Kementerian Pendidikan, Kebudayaan dan Riset Teknologi (Kemdikbudristek) merilis data jumlah sekolah yang terdampak Covid-19 di Indonesia sebanyak 407.000 sekolah dengan 3,4 juta guru serta 56 juta siswa (Prasetyo, 2021)

Kondisi pandemic mampu mengubah wajah pendidikan Indonesia. Praktis pembelejaran tatap muka yang selama ini telah mendarah daging dalam pendidikan kita, harus berganti system dengan pembelajaran online yang memanfaatkan teknologi internet (Kurniasari et al., 2020). Transformasi pembelajaran yang terjadi di masa pandemic Covid-19, sepantasnya dijadikan sebuah momentum positif bagi perbaikan dan pengembangan pembelajaran di perguruan tinggi dalam menghadapi disrupsi revolusi industry 4.0 yang menuntut digitalisasi dan komputasi dengan internet of thing (IoT) (Taufik, 2020).

Perkembangan teknologi digital memberikan pengaruh pada setiap aspek kehidupan manusia (Kejora, 2020), dan melahirkan perkembangan inovasi media social yang dapat digunakan mendukung pembelejaran (Asmawati \& Bintang Kejora, 2020). Penemuan beragam aplikasi atau platform pembelajaran dan media sosial online justru muncul pula pertanyaan, media apa dan bagaimana strategi yang efektif dalam pembelajaran daring?. Dan bagaimana di era teknologi 4.0, pembelajaran mampu memfasilitasi dan membentuk mahasiswa yang nantinya akan terjun ke industri dan siap dengan media digital yang terus berkembang (Hapsari \& Pamungkas, 2019)?.

Saat ini tersedia cukup banyak media yang dapat digunakan untuk pembelajaran online seperti Google Clasroom, Rumah Belajar, Edmodo, Ruang Guru, Zenius, Google Suite for Education, Microsoft Office 365 for Education, Sekolahmu, Kelas intar, Whatsapp, Youtube, dan lainnya (Basori, 2013). Namun salah satu kendala yang muncul adalah perlu waktu untuk mempelajari sistem belajar melalui platform pembelajaran daring tersebut. Sehingga diperlukan pertimbangan efektivitas, efisiensi, dan kemudahan dalam pengoperasian dalam memilih aplikasi atau platform pembelajaran (Daheri et al., 2020).

WhatsApp (WA) menjadi salah satu media sosial yang paling popular yang digunakan oleh masyarakat Indonesia. Hampir semua orang menggunakan WhatsApp sebagai media sosial sehari-hari media (Khusaini et al., 2017). Hal ini membuat komunikasi dan interaksi social melalui pesan, gambar, audio,video, dokumen, dan hal yang unik lainnya termasuk diksusi menjadi lebih mudah (Napratilora et al., 2020). Melalui teknologi pendidikan seluler seperti whatsapp, dapat memfasilitasi pelajar secara online berkesempatan untuk berkomunikasi dan berbagi pengetahuan (Barhoumi, 2020). Mayoritas sebagian besar guru dan siswa di Indonesia menggunakan whatsapp, bahkan pada jenjang sekolah dasar berdasarkan survei $100 \%$ belajar daring memanfaatkan media WhatsApp grup (Sofyana \& Rozaq, 2019).

Studi pendahuluan mengenai pembelajaran Akidah Akhlak di Madrasah Aliyah Swasta (MAS) Ghoyatul Jihad kabupaten Karawang menunjukkan bahwa pembelajaran dilaksanakan dengan berbantuan whatsapp sebagai media pembelajaran sejak awal pandemic. Guru memilih Whatsapp dengan pertimbangan Whatsapp merupakan media platform aplikasi pembelajaran menawarkan kemudahan dan fleksibilitas dalam pengaplikasiannya. Whatsapp dapat didesain sebagai aplikasi pembelajaran elektronik (E-Learning) berbasis open source. Whatsapp dapat difungsikan sebagai ruang kelas online yang seolah-olah dapat mengaktifkan peradan fungsi proses pembelajaran di kelas seperti sumber belajar, menyediakan materi, komunikasi guru dengan siswa, absensi, dan evaluasi. Dengan menggunakan aplikasi Whatsapp mampu mentransformasikan pembelajaran yang bersifat teacher center menjadi student-center (Putra, 2020). 
Whatsapp menawarkan berbagai keunggulan baik sebagai media komunikasi maupun sebagai media pembelajaran daring. Menurut Gon \& Rawekar (2017) dalam laporan penelitiannya, WhatsApp messenger memiliki fitur kolaboratif berikut: 1) Multimedia: memungkinkan pengguna untuk bertukar video, pesan teks, gambar, dan catatan suara; 2) Obrolan Grup: mendukung interaksi hingga 50 anggota kelompok bahkan lebih; 3) Pesan Tak Terbatas: jumlah pesan yang anda dapat berbagi di whatsapp tidak terbatas; 4) Aplikasi menggunakan paket data internet 3G/EDGE atau Wi-Fi untuk memastikan transmisi data terus menerus di seluruh platform; 5) Keterlibatan Lintas Platform: interaksi dengan perangkat yang berbeda (asisten digital pribadi, Smart ponsel, tablet Galaxy) dapat saling mengirim pesan melalui berbagai media (pesan teks, gambar, video, catatan suara); 6) Pesan Offline: pesan disimpan secara otomatis saat perangkat mati atau di luar area jangkauan; 7) Tidak ada Biaya yang terlibat: tidak ada biaya yang terlibat untukmenggunakan WhatsApp karena menggunakan paket data internet yang sama yang digunakan untuk email atau web browsing; 8) Pin dan Nama Pengguna: pengguna WhatsApp tidak perlu ingat kata sandi atau nama pengguna saat berfungsi melalui nomor telepon dan terintegrasi dengan buku kontak pengguna.

Beberapa penelitian lainnya mengenai pemanfaatan whatsapp dalam pembelajaran menunjukkan hasil yang bervariasi. Daheri et al (2020) dalam penelitiannya menunjukkan pembelajaran daring melalui WhatsApp cenderung tidak efektif. Sangat diperlukan evaluasi peran guru juga keterlibatan orang tua. Berbeda dengan penelitian Rahartri (2019), ia menjelaskan WhatsApp lebih efektif dan dirasakan lebih unggul dalam fungsinya sebagai media pembelajaran daring dibanding aplikasi chat lainnya, karena simpel dan mudah dipahami; aplikasi WhatsApp cukup ringan, hemat baterai, dan dapat menghemat data internet. Penelitian Ratnasari et al (2020) menjelaskan bahwa minat dan prestasi belajar peserta didik menggunakan aplikasi Whatsapp dengan materi lebih baik daripada peserta didik yang diajar menggunakan aplikasi Whatsapp tanpa materi.

Berbagai kajian tentang pembelajaran online memanfaatkan aplikasi Whatsapp telah banyak dilakukan. Penelitian lain yang dilakukan di masa pandemi Covid-19 lebih dominan fokus pada dampaknya terhadap proses pembelajaran online dan lebih banyak berfokus pada jenjang sekolah dasar dan perguruan tinggi. Meninjau pada uraian di atas, maka penelitian yang berfokus pada pembelajaran online memanfaatkan media Whatsapp pada pembelajaran Akidah Akhlak di MAS Ghoyatul Jihad Karawang sangat tepat dilakukan. Pasalnya, penelitian pembelajaran online di madrasah sangat jarang dilakukan. Fokus penelitian ini yang juga menjadi permasalahan penelitian ini adalah keterampilan mengajar guru, keaktifan belajar siswa, kemandirian belajar siswa, kendala dalam pembelajaran dan efektivitas pembelajaran menggunakan Whatsapp. Temuan penelitian diharapkan dapat menjadi referensi bagi penelitian selanjutnya dan menjadi bahan evaluasi perbaikan pembelajaran bagi guru dan pengambnil kebijakan mengenai pembelajaran daring berbasis $E$ learning di masa pandemic maupun pada kondisi New Normal.

\section{METODE PENELITIAN}

Penelitian ini merupakan penelitian survei kuantitatif dengan melibatkan 35 siswa kelas X Madrasah Aliyah Swasta Ghoyatul Jihad kabupaten Karawang. Pengumpulan data penelitian melalui survei, wawancara, dokumentasi, dan observasi (Mohajan, 2017). Instrumen penelitian yang digunakan berupa kuesioner melalui googleform, lembar checklist dokumentasi, pedoman wawancara, dan lembar observasi. Sumber data adalah siswa dan guru Akidah Akhlak kelas X. Kusioner berskala likert (1-5) digunakan untuk pengumpulan data persepsi siswa mengenai keterampilan mengajar guru, aktivitas belajar, kemandirian belajar, hambatan dalam pembelajaran dan efektivitas pembelajaran (Suharsaputra, 2012).

Data dianalisis untuk menentukan skor rata-rata setiap item. Kemudian, untuk mengidentifikasi interpretasi verbal rentang skor rata-rata digunakan interval Bringula. Kuesioner terbuka dianalisis menggunakan analisis tematik (Creswell, 2012). Data kualitatif dianalisis dengan teknik deskriptif untuk 
2889 Studi Analisis Pemanfaatan Whatsapp dalam Pembelajaran Daring Akidah Akhlak pada Siswa Madrasah Aliyah - Fikri Firmansyah, Muhamad Taufik Bintang Kejora, Akil

DOI: https://doi.org/10.31004/edukatif.v3i5.1018

memperoleh data yang akurat dan akuntabel dengan mencocokkan data yang diperoleh melalui survei, wawancara, dokumentasi dan observasi yang dipantau dan dibimbing oleh tim peneliti (Creswell, 2014).

Tabel 1. Interprestasi Skor Angket Penelitian

\begin{tabular}{cccc}
\hline No & Rentang Nilai/Skor & $\%$ & Kriteria \\
\hline 1. & $1,00-1,80$ & $20 \%-36 \%$ & Tidak Baik \\
\hline 2. & $1,81-2,60$ & $37 \%-52 \%$ & Kurang Baik \\
\hline 3. & $2,61-3,40$ & $53 \%-68 \%$ & Cukup Baik \\
\hline 4. & $3,41-4,20$ & $69 \%-84 \%$ & Baik \\
\hline 5. & $4,21-5,00$ & $83 \%-100 \%$ & Sangat Baik \\
\hline
\end{tabular}

\section{HASIL DAN PEMBAHASAN PENELITIAN}

Pengumpulan data penelitian menggunakan angket online berbantuan Google form sebagai salah satu alternatif guna mengumpulkan data di tengah kondisi pandemic Covid-19. Pengumpulan data dibantu oleh guru dan ketua siswa agar pengumpulan data terlaksana secara efektif dan efisien. Responden siswa yang terlibat dalam pengumpulan data sebanyak 89 siswa dari 5 rombel kelas yang terdiri dari 33 siswa laki-laki dan 56 siswa perempuan.

\section{Keterampilan Mengajar Guru}

Mengajar, bagi seseorang yang tidak memiliki kompetensi profesional untuk itu, itu akan menghasilkan dosa. Kemudian, jika sesuatu dilakukan oleh sesuatu yang bukan ahlinya, maka tunggulah sampai dihancurkan. Sebuah penggalan hadits Nabi Muhammad, hal ini seolah memberi peringatan kepada guru yang tidak memenuhi kompetensi profesionalnya. Dapat disimpulkan bahwa profesi guru merupakan kewajiban yang hanya dibebankan kepada orang yang berilmu. Dengan demikian, profesi guru harus didasarkan pada adanya kompetensi dan kualifikasi tertentu bagi setiap orang yang ingin mengajar (Suhartini et al., 2021).

Guru dengan kemampuan profesionalnya merupakan faktor yang relevan dalam pelatihan dan persiapan rencana didaktik dan metodis, mengatur dan melakukan pekerjaan pada pembelajaran siswa (Murati, 2015). Dengan kata lain, kesuksesan dan pencapaian tujuan pendidikan menempatkan guru sebagai aktor utama. Untuk dapat mengajar dengan benar, terutama di masa pandemic dengan memanfaatkan aplikasi secara daring, tentunya guru perlu memiliki keterampilan mengajar khusus. Karena kondisi pembelajaran di masa pandemic membutuhkan tindakan solusi yang tidak biasa. Agar pembelajaran dapat terlaksana sesuai tujuan pembelajaran, maka guru harus menguasai keterampilan dasar mengelola pembelajaran. Terdapat 9 keterampilan guru dalam mengajar mencakup: 1) keterampilan membuka dan menutup pelajaran; 2) bertanya; 3) menjelaskan; 4) ) mengadakan variasi; 5) membimbing diskusi kelompok kecil; 6) mengelola kelas; 7) menggunakan media pembelajaran; 8) mengajar kelompok kecil dan individual; dan 9) memberi penguatan (Trimo, 2011).

Untuk mengukur sejauh mana keterampilan guru mengajar Akidah Akhlak menggunakan Whatsapp, dilakukan pengumpulan data menggunakan angket Google form kepada 34 siswa kelas X MAS Ghoyatul Jihad.

Tabel 2. Keterampilan Mengajar Guru

\begin{tabular}{clrrc}
\hline No & \multicolumn{1}{c}{ Keterampilan Mengajar } & Skor & $\%$ & Interprestasi \\
\hline 1 & Keterampilan membuka dan menutup pelajaran & 4,32 & 86,40 & Sangat Baik \\
\hline 2 & Bertanya & 3,84 & 76,80 & Baik \\
\hline 3 & Menjelaskan & 3,54 & 70,80 & Baik \\
\hline 4 & Mengadakan variasi & 3,51 & 70,20 & Baik \\
\hline 5 & Membimbing diskusi kelompok kecil & 3,34 & 66,80 & Baik \\
\hline
\end{tabular}


2890 Studi Analisis Pemanfaatan Whatsapp dalam Pembelajaran Daring Akidah Akhlak pada Siswa Madrasah Aliyah - Fikri Firmansyah, Muhamad Taufik Bintang Kejora, Akil

DOI: https://doi.org/10.31004/edukatif.v3i5.1018

\begin{tabular}{clrrc}
\hline No & Keterampilan Mengajar & Skor & $\%$ & Interprestasi \\
\hline 6 & Mengelola kelas & 3,47 & 69,40 & Baik \\
\hline 7 & Menggunakan media pembelajaran & 4,46 & 89,20 & Sangat Baik \\
\hline 8 & Mengajar kelompok kecil dan individual & 3,39 & 67,80 & Baik \\
\hline 9 & Memberi penguatan & 4,22 & 84,40 & Sangat Baik \\
\hline$\quad$ Rata-Rata & 3,79 & 75,76 & Baik \\
\hline
\end{tabular}

Hasil survei mengenai keterampilan mengajar guru berada pada rata-rata 3,79 atau $75,76 \%$, menunjukkan bahwa keterampilan mengajar guru Akidah Akhlak dalam pembelajaran menggunakan Whatsapp dalam kategori baik. Dari 9 aspek yang dilakukan pengukuran, pada aspek keterampilan membuka dan menutup pelajaran, menggunakan media pembelajaran, dan memberi penguatan terlaksana sangat baik. Sedangkan 6 aspek lain terlaksana dengn baik. Ini membuktikan bahwa guru Akidah Akhlak mampu mengelola pembelajaran dengan mengerahkan keterampilan mengajar yang mengacu kepada tujuan pembelajaran.

\section{Pelaksanaan pembelajaran memanfaatkan Whatsapp dalam pembelajaran Akidah Aklak}

Pembelajaran daring yang secara nasional dipromosikan oleh pemerintah melalui Kementerian Pendidikan dan Kebudayaan (Damayanthi, 2020), sejak awal disikapi guru Akidah Akhlak dengan melakukan pembelajaran memanfaatkan Whatsapp. Beragam keunggulan yang dimiiki menjadi salah satu pertimbangan dipilihnya Whatsapp sebagai moda pembelajaran online di masa pandemic.

Dalam penelitian ini, kami mencoba mengukur pelaksanaan pembelajaran dengan melakukan survey keterlaksanaan pembelajaran dengan mengacu kepada 10 aspek yang direkomendasikan oleh Mustakim (2020) dalam studinya yang menjelaskan agar pendidik dalam melaksanakan pembelajaran berbasis Whatsapp dapat memenuhi sepuluh aspek, yakni: (1) pembelajaran dilakukan melalui video call; (2) pemberian materi pembelajaran yang ringkas; (3) meminimalisir mengirim materi dalam bentuk video berat untuk menghemat kuota; (4) pemilihan materi dalam video harus berdasarkan kriteria bahasa yang mudah dipahami; (5) tetap memberikan materi sebelum penugasan; (6) pemberian soal yang variatif dan berbeda tiap peserta didik; (7) pemberian tugas harus disertakan cara kerjanya; (8) memberikan tugas sesuai dengan jadwal pelajaran; (9) mengingatkan peserta didik jika ada tugas yang diberikan; dan (10) mengurangi tugas.

Tabel 3. Survei Keterlaksanaan Pembelajaran Daring Whatsapp

\begin{tabular}{clccc}
\hline No & \multicolumn{1}{c}{ Keterampilan Mengajar } & Skor & $\%$ & Interprestasi \\
\hline 1 & Pembelajaran dilakukan melalui video call & 3,21 & 64,20 & Cukup \\
\hline 2 & Pemberian materi pembelajaran yang ringkas & 3,84 & 76,80 & Baik \\
\hline 3 & $\begin{array}{l}\text { Meminimalisir mengirim materi dalam bentuk video } \\
\text { berat untuk menghemat kuota }\end{array}$ & 3,55 & 71,00 & Baik \\
\hline 4 & $\begin{array}{l}\text { Pemilihan materi dalam video harus berdasarkan } \\
\text { kriteria bahasa yang mudah dipahami; }\end{array}$ & 3,66 & 73,20 & Baik \\
\hline 5 & Tetap memberikan materi sebelum penugasan & 4,33 & 86,60 & Sangat Baik \\
\hline 6 & $\begin{array}{l}\text { Pemberian soal yang variatif dan berbeda tiap peserta } \\
\text { didik }\end{array}$ & 2,88 & 57,60 & Cukup \\
\hline 7 & Pemberian tugas harus disertakan cara kerjanya & 3,18 & 63,60 & Cukup \\
\hline 8 & Memberikan tugas sesuai dengan jadwal pelajaran & 4,27 & 85,40 & Sangat Baik \\
\hline 9 & $\begin{array}{l}\text { Mengingatkan peserta didik jika ada tugas yang } \\
\text { diberikan }\end{array}$ & 4,67 & 93,40 & Sangat Baik \\
\hline 10 & Mengurangi tugas yang memeberatkan siswa & 3,88 & 77,60 & Baik \\
\hline & Rata-Rata & 3,747 & 74,94 & Baik \\
\hline
\end{tabular}


Hasil survei keterlaksanaan pembelajaran menggunakan Whatsapp berada pada rata-rata 3,7 atau $74,94 \%$, menunjukkan bahwa pembelajaran sudah terlaksana dengan baik. Namun dari 10 poin, terdapat 3 poin yang perlu ditingkatkan dalam pembelajaran yaitu guru harus mempu melakukan pembelajaran secara video call kepada siswa, guru perlu meningkatkan pemberian soal yang variative dan berbeda kepada siswa, dan guru perlu memberikan tugas yang disertai prosedur kerja kepada siswa. Prosentase keterlaksanaan pembelajaran untuk masing-masing indicator dilaporkan sebagai berikut:

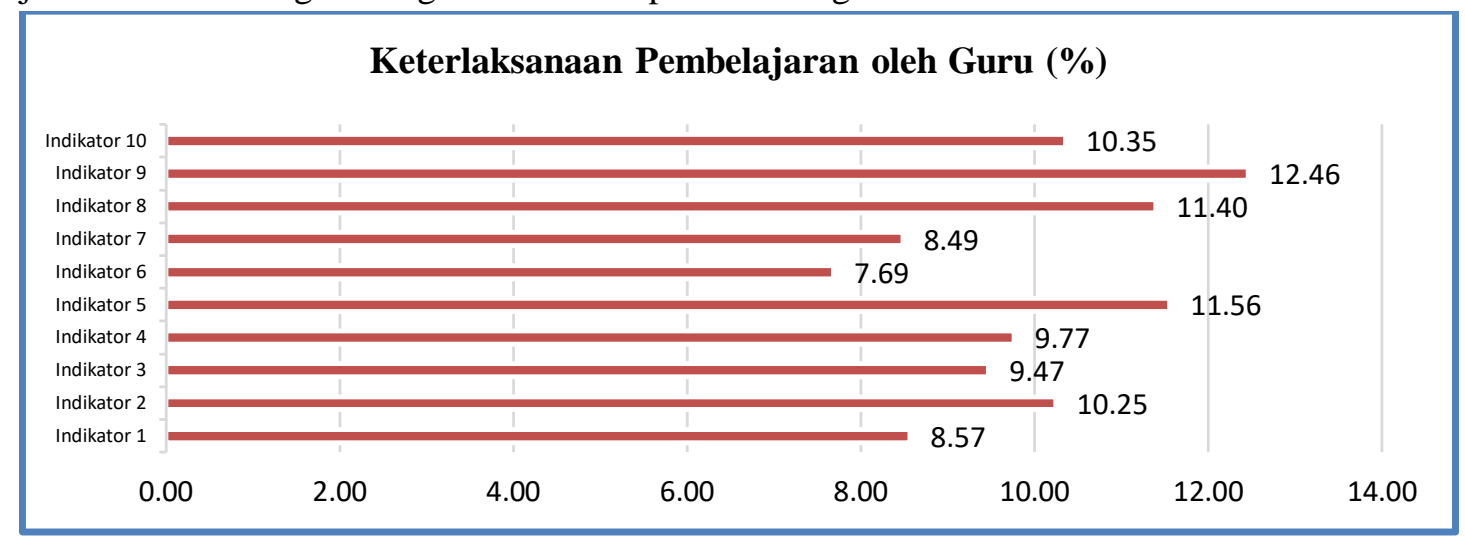

\section{Gambar 1. Prosentase Keterlaksanaan Pembelajaran Online berbasis Whatsapp}

Sedangkan keterlaksanaan pembelajaran Akidah Akhlak secara online memanfaatkan Whatsapp yang dilaksanakan oleh siswa diukur dalam beberapa aspek, diantaranya mencakup kehadiran, kedisiplinan pengumpulan tugas, review pembelajaran, keaktifan, kemandirian, dan interaksi.

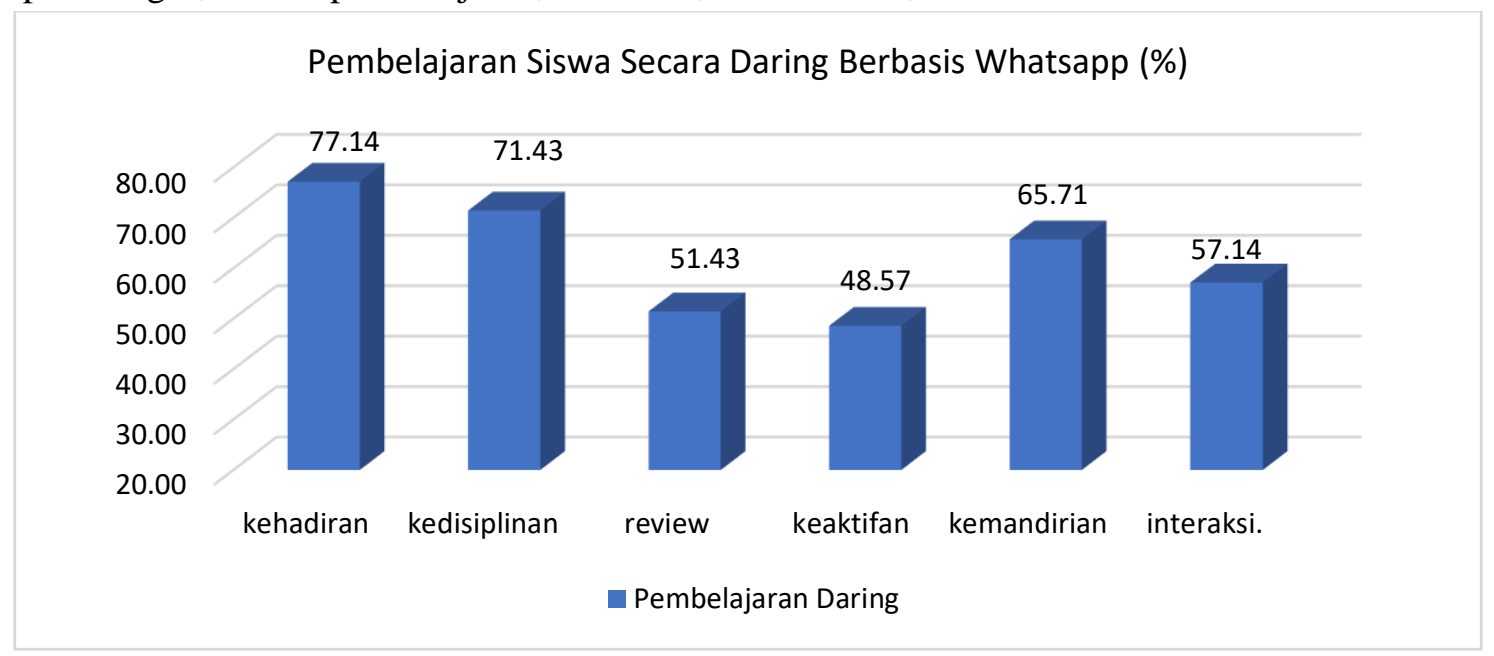

Gambar 2. Pembelajaran Siswa dalam Pembelajaran Daring Berbasis Whatsapp

Hasil survey keterlaksanaan pembelajaran oleh siswa dalam pembelajaran daring Akidah Akhlak memanfaatkan media Whatsapp berada pada rata-rata 2,48 atau $61,90 \%$, menunjukkan bahwa pembelajaran sudah terlaksana dengan cukup baik. Namun dari 6 poin, terdapat 3 poin yang masih perlu ditingkatkan dalam pembelajaran yaitu aktivitas review pembelajaran, keaktifan dalam pembelajaran, dan interaksi dalam pembelajaran.

Guru dalam mengelola pembelajaran berbasis online, perlu memperhatikan tiga hal agar pembelajaran dapat berjalan sukses yaitu (Okmawati, 2020): (1) Pertama, guru secara teratur menghadiri program pengembangan kompetensi pemanfaatan teknologi internet untuk pembelajaran sehingga mereka mendapatkan pengetahuan dan praktik pembelajaran di awal semester atau awal tahun akademik. Guru termotivasi mengikuti lokakarya yang dimulai oleh pengenalan platform, manfaat dan bagaimana mengoperasikannya untuk menopang pembelajaran dalam kondisi daring. Dari program itu, para guru akan memperoleh pemahaman yang lebih dalam tentang aplikasi, maka mereka bisa memaksimalkan dalam 

Aliyah - Fikri Firmansyah, Muhamad Taufik Bintang Kejora, Akil

DOI: https://doi.org/10.31004/edukatif.v3i5.1018

pengoperasiannya sesuai kebutuhan dan capaian pembelajaran baik secara syncronus maupun asyncronus. 2) Kedua, kesadaran untuk transformasi pembelajaran tatap muka menjadi pembelajaran daring juga mendorong para guru untuk mengelola kelas dengan menggunakan teknologi, sehingga pembelajaran tidak membutuhkan banyak kertas dan cetakan lembar kerja. Hal ini tentu sejalan dengan momentum kampanye hijau dengan kemajuan teknologi dan kesadaran untuk dapat mempertahankan konsumsi sumber daya alam. 3) Terakhir, siswa memiliki fasilitas pribadi berupa laptop dan gadget/smartphone yang dapat mendukung kebutuhan pembelajaran daring dan menggantikan ketersediaan buku kerja dan bahan ajar cetak. Ini adalah sifat penggunaan teknologi digital di pembelajaran dimana siswa memanfaatkan digital dan mengurangi ketergantungan pada sumber teks tercetak.

\section{Kesulitan yang dihadapi dalam pembelajaran Akidah Akhlak memanfaatkan Whatsapp}

Pembelajaran daring merupakan model pembelajaran yang dalam aktivitasnya memanfaatkan jaringan internet dengan aksesibilitas, konektivitas, fleksibilitas, dan kemampuan untuk memunculkan berbagai jenis interaksi pembelajaran (Sadikin \& Hamidah, 2020). Akan tetapi pembelajaran menggunakan Whatsapp tentunya memiliki kelemahan atua kendala yang dihadapi oleh siswa. Untuk mengetahui kesulitan yang dihadapi siswa, peneliti merujuk pada hasil penelitian Widodo \& Nursaptini (2020) bahwa kendala yang dihadapi siswa dalam pembelajaran online antara lain koneksi internet, kuota internet terbatas, kurang fokus, penggunaan media daring oleh guru, tugas yang menumpuk, dan jadwal pelajaran tidak teratur. Hasilnya dilaporkan sebagai berikut:

Tabel 4. Kendala Pembelajaran Daring Berbasis Whatsapp

\begin{tabular}{llc}
\hline No & \multicolumn{1}{c}{ Kendala } & \% \\
\hline 1 & Koneksi internet & 22,73 \\
\hline 2 & Kuota internet terbatas & 19,70 \\
\hline 3 & Kurang fokus & 18,18 \\
\hline 4 & Penggunaan media daring oleh guru & 13,64 \\
\hline 5 & Tugas yang menumpuk & 19,70 \\
\hline 6 & Jadwal pelajaran & 6,06 \\
\hline & Jumlah & 100,00 \\
\hline
\end{tabular}

Hasil survei kendala pembelajaran daring menunjukkan bahwa koneksi internet, kuota interenet, dan tugas yang menumpuk menjadi salah satu kendala yang paling umum dialami siswa. Ketika kuota dan koneksi tidak terfasilitasi dengan baik maka secara langsung berdampak pada kurang optimalnya pembelajaran. Ketika guru mengirimkan tugas, maka informasi akan terlambat diterima siswa. Ketika siswa menerima pesan masuk maka akan terjadi penumpukan informasi termasuk tugas.

Sejalan dengan temuan penelitian ini, Daheri et al (2020) dalam kajian penelitiannya menjelaskan hasil bahwa penggunaan WhatsApp sebagai media pembelajaran daring kurang efektif dalam mencapai tujuan pembelajaran. Ketidakefektifan disebabkan oleh kurangnya penjelasan yang komprehensif dan sederhana dari guru, rendahnya aspek afektif dan psikomotorik pada pembelajaran, sinyal internet, dan kuota internet yang dimiliki siswa.

\section{Hasil belajar dan tingkat kepuasan siswa terhadap pembelajaran Akidah Akhlak secara daring memanfaatkan Whatsapp}

Dalam sebuah aktivitas pembelajaran, pencapaian tujuan pembelajaran direpresentasikan dalam bentuk hasil belajar peserta didik. Lebih jelasnya, hasil belajar adalah pernyataan tertulis tentang apa yang diharapkan dapat dicapai oleh siswa/peserta didik yang berhasil di akhir modul program/unit kursus atau kualifikasi (Paolini, 2015). Hasil belajar adalah pernyataan tentang apa yang diharapkan untuk diketahui, dipahami, 
2893 Studi Analisis Pemanfaatan Whatsapp dalam Pembelajaran Daring Akidah Akhlak pada Siswa Madrasah Aliyah - Fikri Firmansyah, Muhamad Taufik Bintang Kejora, Akil

DOI: https://doi.org/10.31004/edukatif.v3i5.1018

dan/atau dapat didemonstrasikan oleh pembelajar setelah menyelesaikan suatu proses pembelajaran (Mahajan \& Singh, 2017).

Pembelajaran Akidah Akhlak secara daring menggunakan Whatsapp, mengevaluasi proses pembelajaran dan menginterprestasikannya ke dalam hasil belajar yang dicapai siswa. Kriteria ketuntasan minimal (KKM) ditetapkan pada nilai 70. Hasilnya dilaporkan sebagai berikut:

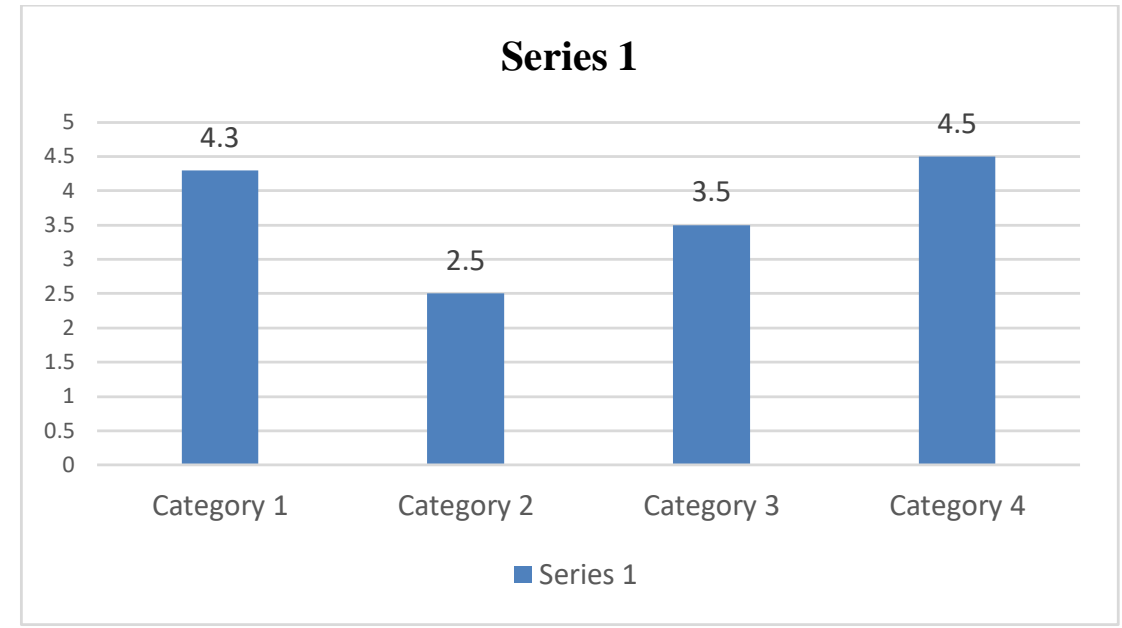

Gambar 3. Prosentase Perolehan Hasil Belajar

Berdasarkan data, rata-rata hasil belajar siswa secara kumulatif atau klasikal 81,13 menunjukkan hasil belajar siswa dalam pembelajaran daring menggunkan Whatsapp pada pembelajaran Akidah Akhlak dalam kategori baik. Terdapat 6 siswa dengan nilai dibawah KKM, 5 siswa dengan nilai cukup, 15 siswa dengan nilai baik, dan 9 siswa dengan nilai sangat baik.

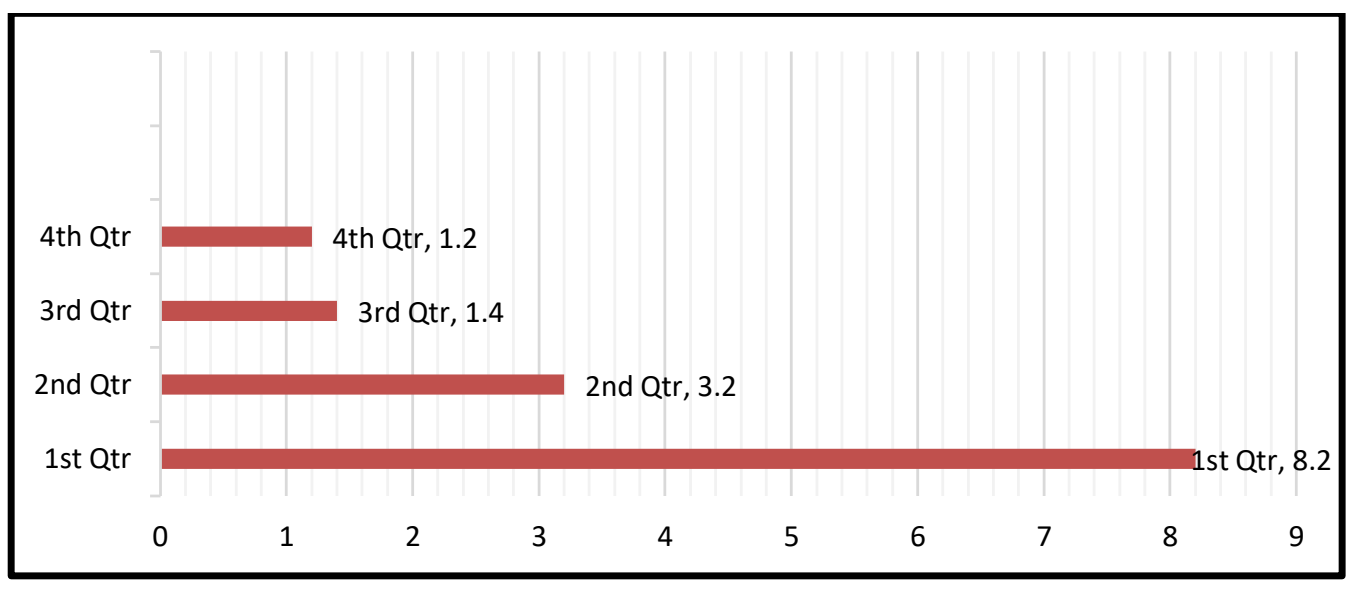

Gambar 4. Evaluasi Proses Pembelajaran Daring berbasis Whatsapp

Hasil evaluasi guru terhadap proses pembelajaran daring menggunkaan Whatsapp yang dilaksanakan siswa diukur dalam 6 aspek yaitu pengumpulan tugas individu, pengumpulan tugas kelompk, presentasi, praktik, UTS dan UAS. Hasilnya secara kumulatif berada pada rata-rata 81,16. Ini menunjukkan hasil belajar siswa ditinjau dari proses pembelajaran berada pada kategori baik.

Selanjutnya yang tidak kalah penting adalah respon kepuasan siswa mengenai pembelajaran PAI memanfaatkan Google Classroom selama masa pandemic Covid-19. Hasil survei kepuasan siswa menunjukkan jumlah siswa yang merespon sangat puas dan puas berjumlah 26 orang $(74,29 \%)$. Artinya siswa merasa puas terhadap pembelajaran daring berbasis Whatsapp pada pembelajaran Akidah akhlak. 
2894 Studi Analisis Pemanfaatan Whatsapp dalam Pembelajaran Daring Akidah Akhlak pada Siswa Madrasah Aliyah - Fikri Firmansyah, Muhamad Taufik Bintang Kejora, Akil

DOI: https://doi.org/10.31004/edukatif.v3i5.1018

Tabel 5. Survei Kepuasan Siswa

\begin{tabular}{lcc}
\hline \multicolumn{1}{c}{ Respon Kepuasan Siswa } & Jumlah Siswa & \% \\
\hline Sangat Puas & 17 & 48,57 \\
\hline Puas & 9 & 25,71 \\
\hline Kurang Puas & 7 & 20,00 \\
\hline Tidak Puas & 2 & 5,71 \\
\hline
\end{tabular}

Hasil penelitian menunjukkan bahwa whatsapp menjadi media pembelajaran yang efektif dalam pembelajaran PAI secara daring. Keefektifan media whatsapp ditunjukkan oleh hasil belajar 81,13 (Baik) dan tingkat kepuasan siswa yang tinggi. Hasil penelitian ini sejalan dengan temuan penelitian Gon \& Rawekar (2017) yang menjelaskan ketersediaan konstan fasilitator dan pembelajaran yang fleksible dapat dilaksnaakn kapan saja di mana saja, telah membuat WhatsApp menjadi media yang efektif dan nyaman untuk kegiatan belajar mengajar.

Efektivitas whatsapp dalam pembelajaran PAI secara daring didukung oleh keterampilan mengajar guru yang baik $(3,79)$ dan proses pembelajaran yang menyenangkan bagi siswa $(3,74)$. Faktor lain adalah kesadaran siswa untuk disiplin, mandiri, dan aktif dalam pembelajaran $(2,48)$. Analisa dan temuan ini sejalan dengan hasil penelitian Nguyen (2017), pemanfaatan Whatsapp dalam pembelajaran daring akan efektif dan efisien manakala ditunjang dengan ketersediaan fasilitas belajar yang memadai, desain konten pembelajaran yang inovatif dan desain pembelajaran yang membuat siswa aktif dan merasakan kegembiraan sehingga siswa tidak jenuh dan termitivasi untuk belajar. Daheri et al (2020) dalam simpulan penelitiannya mengenai pemanfaatan media Whatsapp dalam pembelajaran mengungkap bahwa penggunaan WhatsApp sebagai media pembelajaran daring kurang efektif dalam mencapai tujuan pembelajaran. Hal ini disebabkan berbagai faktor, diantaranya kurangnya penjelasan yang komprehensif dan sederhana dari guru, rendahnya aspek afektif dan psikomotorik pada pembelajaran, sinyal internet, kesibukan orang tua dan latar belakang pendidikan orang tua.

Beberapa kendala pembelajaran daring juga dialami dalam pembelajaran PAI menggunakan Whatsapp seperti koneksi internet, kuota interenet, dan tugas yang menumpuk. Secara sederhana ketika siswa mengalami koneksi internet yang buruk atau kehabisan kuota internet, maka mereka tidak dapat mengikuti pembelajaran dengan baik. Siswa kehilangan kesempatan belajar dan penjelasan mengenai tugas yang diberikan guru. Dampaknya adalah siswa mengalami tugas yang menumpuk, baik tugas PAI maupun dengan tugas mata pelajaran lainnya. Kondisi belejar semacam ini memberi dampak psikologis bagi siswa seperti jenuh, bosan bahkan stress ketika belajar (Widodo \& Nursaptini, 2020).

Sejalan dengan penelitian Khusaini et al. (2017), penelitian ini menemukan bahwa penggunaan Whatsapp dalam pembelajaran dapat membantu siswa untuk saling berdiskusi dengan sesama siswa lainnya maupun dengan guru. Kesempatan belajar maupun mengakses materi dapat berjalan lebih efektif serta dapat dilakukan kapanpun dan dimanapun. Penggunaan Whatsapp juga dapat dilakukan untuk melakukan penilaian teman sejawat. Siswa dapat melakukan penilaian secara langsung serta dapat melihat masukan secara isntan tanpa harus menunggu waktu yang lama.

Hasil penelitian ini, dapat dijadikan bahan mengevaluasi pembelajaran yang dilaksanakan guru dan siswa pada pembelajaran Akidah Akhlak berbantuan Whatsapp. Guru dapat mengukur kelebihan dan kekurangan pembelajaran yang dilaksanakan sehingga membantu guru dalam perbaikan dan tindak lanjut pembelajaran pada tahap selanjutnya. Temuan penelitian ini dapat merekomendasikan aspek-aspek atau indicator yang perlu diteliti terkait pemanfaatan media online khususnya Whatsapp dalam pembelajaran di masa pandemic. Namun perlu diakui bahwa penelitian yang dilakukan masih terbatas pada pembelajaran Akidah Akhlak pada siswa kelas X Madrasah Aliyah Swasta Ghoyatul Jihad kabupaten Karawang dengan sample 35 siswa. Penelitian lanjutan sebaiknya dilakukan untuk mengkaji penggunaan Whatsapp dengan 
2895 Studi Analisis Pemanfaatan Whatsapp dalam Pembelajaran Daring Akidah Akhlak pada Siswa Madrasah Aliyah - Fikri Firmansyah, Muhamad Taufik Bintang Kejora, Akil

DOI: https://doi.org/10.31004/edukatif.v3i5.1018

cakupan subjek yang lebih kompleks, aspek yang lebih luas dan objek penelitian yang lebih general. Sehingga hasil penelitian selanjutnya dapat memberikan informasi yang lebih komprehensif.

\section{KESIMPULAN}

Pemanfaatan Whatsapp sebagai media pembelajaran mampu secara efektif memfasilitasi kebutuhan belajar siswa madrasah Aliyah pada mata pelajaran Akidah Akhlak MAS Ghoyatul Jihad Karawang selama masa pandemic. Keterampilan mengajar dan kemampuan guru mengelola pembelajaran dengan berbantuan Whatsapp menjadi faktor kunci dalam kesuksesan pembelajaran. Namun demikian guru perlu pula memperbaiki 3 aspek yaitu kemampuan melakukan pembelajaran secara video call, pemberian soal yang variative, dan kejelasan prosedur pengerjaan tugas kepada siswa. Penilaian siswa mengenai pembelajaran menggambarkan bahwa guru sudah mampu mengaplikasikan Whatsapp dan mengkolaborasikannya dengan media pendukung lainnya dalam pembelajaran. Kendati siswa mengalami kesulitan akses internet dan kuota serta merasakan menumpuknya tugas, namun pada kenyataannya siswa mampu mengumpulkan tugas dengan baik, merasa puas dengan pembelajaran yang dilaksanakan dan berhasil memperoleh hasil belajar yang memuaskan/baik secara kumulatif/klasikal.

\section{DAFTAR PUSTAKA}

Asmawati, E., \& Bintang Kejora, M. T. (2020). The Effect Of Using Simple Aircraft Concrete Media On The Mastery Of Concepts In Inquiry Science Learning In Elementary School Students. MUDARRISA: Jurnal Kajian Pendidikan Islam, 12(2), 150-168. Https://Doi.Org/10.18326/Mdr.V12i2.150-168

Barhoumi, C. (2020). The Effectiveness Of Whatsapp Mobile Learning Activities Guided By Activty Theory On Students' Knowldege Management. Contemporary Educational Technology, 6(3), 221-238. Https://Doi.Org/10.30935/Cedtech/6151

Basori, B. (2013). Pemanfaatan Social Learning Network "Edmodo" Dalam Membantu Perkuliahan Teori Bodi Otomotif Di Prodi Ptm Jptk Fkip Uns. Jurnal Ilmiah Pendidikan Teknik Dan Kejuruan, 6(2). Https://Doi.Org/10.20961/Jiptek.V6i2.12562

Creswell, J. W. (2014). Research Design Qualitative, Quantitative, And Mixed Method Approaches. SAGE Publication. Inc.

Daheri, M., Juliana, J., Deriwanto, D., \& Amda, A. D. (2020). Efektifitas Whatsapp Sebagai Media Belajar Daring. Jurnal Basicedu, 4(4), 775-783. Https://Doi.Org/10.31004/Basicedu.V4i4.445

Damayanthi, A. (2020). Efektivitas Pembelajaran Daring Di Masa Pandemi Covid 19 Pada Perguruan Tinggi Keagamaan Katolik. JURNAL SOSIAL :Jurnal Penelitian Ilmu-Ilmu Sosial, 21(3), 53-56. Http://Sosial.Unmermadiun.Ac.Id/Index.Php/Sosial/Article/View/61

Gon, S., \& Rawekar, A. (2017). Effectivity Of E-Learning Through Whatsapp As A Teaching Learning Tool. MVP Journal Of Medical Sciences, 4(1), 19. Https://Doi.Org/10.18311/Mvpjms/0/V0/I0/8454

Hapsari, S. A., \& Pamungkas, H. (2019). Pemanfaatan Google Classroom Sebagai Media Pembelajaran Online Di Universitas Dian Nuswantoro. WACANA: Jurnal Ilmiah Ilmu Komunikasi, 18(2). Https://Doi.Org/10.32509/Wacana.V18i2.924

Kejora, M. T. B. (2020). The Use Of Concrete Media In Science Learning In Inquiry To Improve Science Process Skills For Simple Machine Subject. MUDARRISA: Jurnal Kajian Pendidikan Islam, 12(1), 117. Https://Doi.Org/10.18326/Mdr.V12i1.1-17

Khusaini, K., Suyudi, A., Winarto, W., \& Sugiyanto, S. (2017). Optimalisasi Penggunaan Whatsapp Dalam Perkuliahan Penilaian Pendidikan Fisika. Jurnal Riset Dan Kajian Pendidikan Fisika, 4(1), 1. Https://Doi.Org/10.12928/Jrkpf.V4i1.6462 
2896 Studi Analisis Pemanfaatan Whatsapp dalam Pembelajaran Daring Akidah Akhlak pada Siswa Madrasah Aliyah - Fikri Firmansyah, Muhamad Taufik Bintang Kejora, Akil

DOI: https://doi.org/10.31004/edukatif.v3i5.1018

Kurniasari, A., Pribowo, F. S. P., \& Putra, D. A. (2020). Analisis Efektivitas Pelaksanaan Belajar Dari Rumah (Bdr) Selama Pandemi Covid-19. Jurnal Review Pendidikan Dasar: Jurnal Kajian Pendidikan Dan Hasil Penelitian, 6(3), 1-8.

Mahajan, M., \& Singh, M. K. S. (2017). Importance And Benefits Of Learning Outcomes. IOSR Journal Of Humanities And Social Science, 22(03), 65-67. Https://Doi.Org/10.9790/0837-2203056567

Mohajan, H. K. (2017). Aspects Of Mathematical Economics, Social Choice And Game Theory: Jamal Nazrul Islam Research Centre For Mathematical Research. Journal Of Economic Development, Environment And People, March, 2009-2010.

Murati, R. (2015). The Role Of The Teacher In The Educational Process. The Online Journal Of New Horizon In Education, 5(2), 75-78.

Mustakim, M. (2020). Efektivitas Pembelajaran Daring Menggunakan Media Online Selama Pandemi Covid19 Pada Mata Pelajaran Matematika. Al Asma: Journal Of Islamic Education, 2(1), 1. Https://Doi.Org/10.24252/Asma.V2i1.13646

Napratilora, M., Lisa, H., \& Bangsawan, I. (2020). Using Whatsapp As A Learning Media In Teaching Reading. $\quad$ MITRA PGMI: Jurnal Kependidikan MI, 6(2), 116-125. Https://Doi.Org/10.46963/Mpgmi.V6i2.129

Nguyen, V. A. (2017). The Impact Of Online Learning Activities On Student Learning Outcome In Blended Learning Course. Journal of Information And Knowledge Management, 16(4). Https://Doi.Org/10.1142/S021964921750040X

Novianti E, Fatkhia Alda Rizka, \& Nuryana Zalik. (2020). Analisis Kebijakan Pembelajaran Di Masa Pandemi. Jurnal Pendidikan Islam , 11(2), 201-211. Http://Journal.Uhamka.Ac.Id/Index.Php/Jpi

Okmawati, M. (2020). The Use Of Google Classroom During Pandemic. Journal Of English Language Teaching, 9(2), 438. Https://Doi.Org/10.24036/Jelt.V9i2.109293

Paolini, A. (2015). Enhancing Teaching Effectiveness And Student Learning Outcomes. The Journal Of Effective Teaching, 15(1), 20-33.

Prasetyo, B. W. (2021). Kemdikbudristek: 407.000 Sekolah Dan 56 Juta Siswa Terdampak Pandemi. Beritasatu.Com. Https://Www.Beritasatu.Com/Nasional/769773/Kemdikbudristek-407000-SekolahDan-56-Juta-Siswa-Terdampak-Pandemi

Putra, N. P. (2020). Solusi Pembelajaran Jarak Jauh Menggunakan Aplikasi Zoom Dan Whatsapp Group Di Era New Normal Pada Warga Belajar Paket C Di Pusat Kegiatan Belajar Masyarakat (PKBM) BINA INSANI Nugraha. Jipsindo, 7(2), 162-176.

Rahartri. (2019). "Whatsapp" Media Komunikasi Efektif Masa Kini (Studi Kasus Pada Layanan Jasa Informasi Ilmiah Di Kawasan Puspiptek). Visi Pustaka, 21(2), 147-156.

Ratnasari, D., Ponoharjo., \& Utami, W. B. (2020). Penerapan Aplikasi Whatsapp Terhadap Minat Dan Prestasi Peserta Didik. Jurnal Edukasi Dan Sains Matematika, 6(2), 129-138.

Sadikin, A., \& Hamidah, A. (2020). Pembelajaran Daring Di Tengah Wabah Covid-19. Biodik, 6(2), 109-119. Https://Doi.Org/10.22437/Bio.V6i2.9759

Sofyana, L., \& Rozaq, A. (2019). Pembelajaran Daring Kombinasi Berbasis Whatsapp Pada Kelas Karyawan Prodi Teknik Informatika Universitas Pgri Madiun. Jurnal Nasional Pendidikan Teknik Informatika (JANAPATI), 8(1), 81-86. Https://Doi.Org/10.23887/Janapati.V8i1.17204

Suharsaputra, U. (2012). Metode Penelitian Kuantitaif Kualitatif Dan Tindakan. Refika Adhitama.

Suhartini, S., Milfayetty, S., \& Rahman, A. (2021). The Effect Of Teacher Professionalism And Competency On The Quality Of Education In The City Of Langsa. Budapest International Research And Critics Institute (BIRCI-Journal): Humanities And Social Sciences, 4(2), 2271-2276. Https://Doi.Org/10.33258/Birci.V4i2.1921 
2897 Studi Analisis Pemanfaatan Whatsapp dalam Pembelajaran Daring Akidah Akhlak pada Siswa Madrasah Aliyah - Fikri Firmansyah, Muhamad Taufik Bintang Kejora, Akil DOI: https://doi.org/10.31004/edukatif.v3i5.1018

Taufik, M. (2020). Strategic Role Of Islamic Religious Education In Strengthening Character Education In The Era Of Industrial Revolution 4.0. Jurnal Ilmiah Islam Futura, 20(1), 86. Https://Doi.Org/10.22373/Jiif.V20i1.5797

Trimo, T. (2011). Peningkatan Keterampilan Dasar Mengajar Guru Melalui Supervisi Klinis Di Sdn 1 Magelung Kabupaten Kendal. Jurnal Penelitian Pendidikan Unnes, 28(1), 124987. Https://Doi.Org/10.15294/Jpp.V28i1.5617

Widodo, A., \& Nursaptini. (2020). Problematika Pembelajaran Daring Dalam Perspektif Mahasiswa. ELSE (Elementary School Education Journal), 04(02), 100-115. 